\title{
Insulin Resistance Contributes to Obesity-Related Proteinuria
}

\author{
Hiroshi Matsumoto, Toshiyuki NAKAO, Tomonari OKADA, Yume NAGAOKA, \\ Hideaki IwASAwA, Ryo TOMARU and Toshikazu WADA
}

\begin{abstract}
Objective Proteinuria is a recognized complication of obesity, but the pathogenesis remains unclear. We undertook the present study to clarify the factors contributing to proteinuria associated with obesity.

Methods We studied 12 obese patients with proteinuria. Twenty-seven age-matched obese subjects without proteinuria served as controls. A glucose tolerance test and renal biopsy were performed in all patients. Fasting serum insulin and homeostasis model assessment-insulin resistance (HOMA-IR) were regarded as reflecting insulin resistance. To delineate the relation between insulin resistance and proteinuria, troglitazone, which acts an insulin sensitizer was given to 6 of 12 patients with a regular diet for 8 weeks. The 6 others were observed without receiving troglitazone.

Results The 12 patients showed the presence of a cluster of insulin resistance factors: higher blood pressure, higher body mass index, higher fasting plasma glucose, higher fasting serum insulin, and higher HOMA-IR than controls. The renal biopsy specimens exhibited no histological abnormalities in 7, focal segmental glomerulosclerosis in 3 and benign nephrosclerosis in 2 . Troglitazone attenuated HOMA-IR and ameliorated proteinuria, but did not affect body weight, creatinine clearance, or blood pressure. In contrast, the parameters in the patients not given troglitazone did not change.

Conclusion Insulin resistance is a factor contributing to obesity-related proteinuria. The role of insulin resistance as a factor reducing proteinuria remains to be clarified.

(Internal Medicine 44: 548-553, 2005)
\end{abstract}

Key words: overweight, proteinuria, insulin resistance, minor glomerular abnormality, troglitazone

\section{Introduction}

Obesity has been recognized as a culprit of proteinuria and glomerulopathy (1-3). Obesity-related proteinuria or glomerulopathy had been considered to be limited to a very small population, but it has been dramatically increasing according to a recent report (4). In addition, obesity is associated with glomerular hyperfiltration (5). Glomerular hyperfiltration is well known to be related to proteinuria and glomerulosclerosis, and these long standing glomerular hemodynamic abnormalities seem to be a prerequisite for the occurrence of glomerular injury. However, the determinants remain still unknown. Obesity predisposes to insulin resistance and resultant hyperinsulinemia (6). Experimental studies have documented the direct effect of insulin on glomerular microcirculation (7). In the present study, we tested the hypothesis that obesity-related proteinuria is associated with insulin resistance, and whether or not troglitazone, an agent that can reduce insulin resistance, ameliorates urinary protein excretion.

\section{Patients and Methods}

\section{Patients}

Twelve obese patients with proteinuria aged 24 to 63 years (mean $44 \pm 10$ years) were studied. All patients with proteinuria (urinary albumin excretion of more than 300 $\mathrm{mg}$ /day) underwent percutaneous renal biopsy under ultrasonographic guidance. Controls consisted of 27 age- and sex-matched obese subjects without proteinuria. The patients and subjects all met the following criteria: body mass index of over $26.4 \mathrm{~kg} / \mathrm{m}^{2}$, normal ultrasonographic imaging of the kidney, normal renal function (creatinine clearance of over $80 \mathrm{ml} / \mathrm{min}$ ), and absence of urinary tract infection, previous history of glomerulonephritis, edema, heart disease, previous history of diabetes and current medications. The study was performed between July 1997 and January 1998 before the

From the Department of Nephrology, Tokyo Medical University, Tokyo

Received for publication March 12, 2004; Accepted for publication January 13, 2005

Reprint requests should be addressed to Dr. Hiroshi Matsumoto, the Department of Nephrology, Tokyo Medical University, 6-7-1 Nishi-shinjuku, Shinjukuku, Tokyo 160-0023 
sale of troglitazone, an agent that reduces insulin resistance, was banned for its serious liver toxicities in March 2000. All participants gave their informed consent and the study was carried out in accordance with the Declaration of Helsinki as revised in 1996.

\section{Methods}

Urinary albumin excretion (mg/day), urinary protein excretion (g/day), and creatinine clearance $(\mathrm{ml} / \mathrm{min})$ were determined from 24-hour urine samples on 2 consecutive days. A 24-hour urine sample was collected at home. The fractional urine was measured after voiding in a scale cup by the subjects. An aliquot of the total sample was brought to the hospital at the end of urine collection.

Blood samples were obtained from an antecubital vein between 9:00 and 10:00 AM after overnight fasting. Plasma glucose was determined by the glucose oxidase method. Total cholesterol, HDL cholesterol, and triglyceride were measured by the enzymatic method. LDL cholesterol was calculated using the Friedewald formula. Serum insulin was measured by means of radioimmunometric assay (Insulin RIA-BEAD II, Dinabot Co., Tokyo, Japan). After the fasting blood specimen was taken, a glucose tolerance test was performed in all patients. At 30 minutes, 60 minutes, 90 minutes and 120 minutes after $75 \mathrm{~g}$ of oral glucose (Trelan G; Shimizu Pharmaceutical Inc., Shimizu, Japan), blood samples were obtained to determinate postloading serum insulin and glucose levels. The patients were classified into 1 of 3 categories, normal type; borderline type; and diabetic type, according to the criteria of the Committee for the Classification and Diagnosis of Diabetes Mellitus of the Japan Diabetes Society (8). Normal type was defined as having a fasting plasma glucose $<110 \mathrm{mg} / \mathrm{dl}(<6.1 \mathrm{mmol} / \mathrm{l})$ and a 2 hour plasma glucose $<140 \mathrm{mg} / \mathrm{dl}(<7.8 \mathrm{mmol} / l)$, whereas diabetic type was defined as having a fasting plasma glucose $\geq 126 \mathrm{mg} / \mathrm{dl}(\geq 7.0 \mathrm{mmol} / \mathrm{l})$ and/or a 2-hour plasma glucose $\geq 200 \mathrm{mg} / \mathrm{dl}(\geq 11.1 \mathrm{mmol} / \mathrm{l})$. Borderline type included those who were neither the normal nor diabetic type.

Arterial blood pressure was measured three times after patients rested for at least five minutes while sitting, using a standard mercury sphygmomanometer. The mean of three measurements was used for the analysis. Mean arterial pressure was calculated as $1 / 3$ the pulse pressure added to the diastolic pressure. Homeostasis model assessment-insulin resistance (HOMA-IR) was calculated as fasting plasma glucose $(\mathrm{mmol} / \mathrm{l}) \times$ fasting serum insulin $(\mathrm{mU} / \mathrm{l} / 22.5)$ as described previously (8). In this study, HOMA-IR was considered to reflect insulin resistance, as HOMA-IR has been shown to have a strong correlation with insulin sensitivity (9). Hyperinsulinemia (elevated fasting serum insulin or the sum of serum insulin at 30 minutes, 60 minutes, 90 minutes and 120 minutes after a $75 \mathrm{~g}$ glucose load) was also interpreted to reflect insulin resistance, as single insulin samples are inversely correlated with insulin sensitivity or whole-body glucose uptake as measured using a euglycemic-hyperinsulinemic clamp or frequently sampled intravenous glucose tolerance test methods (10).

Renal tissue was processed for light, immunofluorescent and electron microscopy according to standard techniques. Focal segmental glomerulosclerosis was diagnosed when typical hyalinized lesions were present. Minimal change disease was diagnosed when pathologic abnormalities were limited.

To address the relation between insulin resistance and proteinuria, troglitazone, an agent that reduces insulin resistance, was given orally for 8 weeks at a dose of $400 \mathrm{mg}$ twice a day. The twelve patients were randomly allocated to one of two groups with or without troglitazone. All patients maintained their regular diet during the study. Fasting plasma glucose, fasting serum insulin, HOMA-IR, creatinine clearance and body weight were assessed at baseline (before therapy), 8 weeks after starting therapy, and 8 weeks after ending therapy. A blood sample and a 24-hour urine sample were obtained on two consecutive days.

\section{Statistical Analysis}

The results were expressed as means $\pm \mathrm{SD}$. Baseline clinical variables between the 2 groups were compared by the unpaired Student's $t$-test or by a chi-square test for stratified data. The Mann-Whitney $U$ test was used when variables were not normally distributed in the 2 groups. The Wilcoxon single-rank test was used for paired comparison. The changes of parameters by administration of troglitazone between the two groups were analyzed by repeated-measurement analysis of variance (ANOVA). Relationship of parameters was evaluated by Pearson liner co-relation coefficients. A $P$ value of less than 0.05 was taken to indicate a statistically significant difference. All statistical calculations were performed on a Macintosh personal computer using StatView 5.0 statistical software.

\section{Results}

Tables 1 and 2 show the clinical characteristics of the obese patients with proteinuria and obese controls. The obese patients had a higher body mass index, and mean arterial pressure than controls. The creatinine clearance was similar in both groups. The obese patients showed the presence of a cluster of insulin resistance factors: a higher prevalence of borderline type/diabetic type, higher fasting plasma glucose, higher fasting serum insulin, and higher HOMA-IR than controls. Serum levels of lipids were statistically similar.

Table 3 shows the clinical characteristics and histological findings in obese patients with proteinuria. Renal tissue was available for histological examination in all 12 patients with proteinuria. The number of glomeruli available for examination ranged from 8 to $27(16 \pm 6)$. No renal biopsy specimens showed the characteristics of diabetic nephropathy. In 7, no glomerular abnormalities (minimal change) were found on light microscopy and global sclerosis was less prevalent (2.1\%); there was no immunofluorescence. Focal segmental glomerulosclerotic (FSGS) lesions were observed in 3 cases 
MATSUMOTO et al

Table 1. Characteristics of Obese Controls and Obese Patients with Proteinuria

\begin{tabular}{|c|c|c|c|}
\hline & $\begin{array}{l}\text { Obese controls } \\
\qquad \mathrm{N}=27\end{array}$ & $\begin{array}{l}\text { Obese patients with proteinuria } \\
\qquad \mathrm{N}=12\end{array}$ & $P$ values \\
\hline Age, year & $43 \pm 8$ & $44 \pm 12$ & NS \\
\hline Gender, female/male & $10 / 17$ & $4 / 8$ & NS \\
\hline Mean arterial pressure, $\mathrm{mmHg}$ & $96 \pm 12$ & $103 \pm 10$ & $<0.01$ \\
\hline Body mass index, $\mathrm{kg} / \mathrm{m}^{2}$ & $28.3 \pm 1.9$ & $31.0 \pm 3.0$ & $<0.01$ \\
\hline Urinary albumin excretion, $\mathrm{mg} /$ day & $18.5 \pm 5.1$ & $842.1 \pm 403.7$ & $<0.01$ \\
\hline Creatinine clearance, $\mathrm{ml} / \mathrm{min}$ & $137 \pm 24$ & $129 \pm 20$ & NS \\
\hline Total cholesterol, mg/dl & $207 \pm 28$ & $222 \pm 30$ & NS \\
\hline Triglyceride, $\mathrm{mg} / \mathrm{dl}$ & $178 \pm 117$ & $204 \pm 65$ & NS \\
\hline HDL-cholesterol, mg/dl & $53 \pm 14$ & $48 \pm 9$ & NS \\
\hline LDL-cholesterol, mg/dl & $120 \pm 27$ & $135 \pm 34$ & NS \\
\hline
\end{tabular}

Table 2. Glucose and Insulin Profiles of Obese Controls and Obese Patients with Proteinuria

\begin{tabular}{lccc}
\hline & $\begin{array}{c}\text { Obese controls } \\
\mathrm{N}=27\end{array}$ & $\begin{array}{c}\text { Obese patients with proteinuria } \\
\mathrm{N}=12\end{array}$ & $P$ values \\
\hline Normal-type/Boderline-type or & $16 / 11^{*}$ & $1 / 11^{\dagger}$ & $<0.01$ \\
Diabetic-type, numbers & $96 \pm 11$ & $110 \pm 15$ & $<0.01$ \\
Fasting glucose, mg/dl & $7.7 \pm 2.9$ & $12.6 \pm 2.8$ & $<0.01$ \\
Fasting insulin, mU/l & $217 \pm 88$ & $520 \pm 433$ & $<0.01$ \\
Total insulin, mU/l & $1.8 \pm 0.7$ & $3.5 \pm 0.7$ & $<0.01$ \\
HOMA-IR & & & \\
\hline
\end{tabular}

*No patient was diabetic type. "Two patients were diabetic type.

Table 3. Clinical Characteristics of Obese Patients with Proteinuria

\begin{tabular}{|c|c|c|c|c|c|c|c|c|c|}
\hline Patients & $\begin{array}{l}\text { Age, } \\
\text { year }\end{array}$ & $\begin{array}{l}\text { Gender, } \\
\text { female/ } \\
\text { male }\end{array}$ & $\begin{array}{l}\text { Body mass } \\
\text { index, } \\
\mathrm{kg} / \mathrm{m}^{2}\end{array}$ & $\begin{array}{l}\text { Systolic blood } \\
\text { pressure, } \\
\text { mmHg }\end{array}$ & $\begin{array}{c}\text { Diastolic blood } \\
\text { pressure } \\
\text { mmHg }\end{array}$ & $\begin{array}{c}\text { Creatinine } \\
\text { clearance, } \\
\mathrm{ml} / \mathrm{min}\end{array}$ & $\begin{array}{l}\text { Urinary } \\
\text { protein, } \\
\text { g/day }\end{array}$ & Renal histology & $\begin{array}{l}\text { Administration } \\
\text { of troglitazone }\end{array}$ \\
\hline 1 & 53 & female & 27.5 & 132 & 70 & 140 & 0.63 & minimal change & + \\
\hline 2 & 29 & male & 35 & 136 & 90 & 120 & 0.5 & minimal change & - \\
\hline 3 & 24 & male & 29.3 & 110 & 74 & 146 & 1.1 & minimal change & + \\
\hline 4 & 35 & male & 26.8 & 146 & 95 & 135 & 0.88 & minimal change & - \\
\hline 5 & 48 & male & 30 & 138 & 90 & 153 & 0.59 & minimal change & + \\
\hline 6 & 50 & female & 32.3 & 160 & 100 & 160 & 1.56 & minimal change & - \\
\hline 7 & 39 & female & 36.4 & 140 & 108 & 131 & 0.49 & minimal change & - \\
\hline 8 & 33 & male & 33.5 & 142 & 98 & 121 & 2.2 & FSGS & + \\
\hline 9 & 46 & male & 28.1 & 140 & 90 & 126 & 0.86 & FSGS & - \\
\hline 10 & 60 & male & 30.9 & 144 & 100 & 130 & 1.12 & FSGS & + \\
\hline 11 & 60 & female & 29 & 164 & 94 & 108 & 1.39 & nephrosclerosis & + \\
\hline 12 & 48 & male & 32.6 & 140 & 90 & 87 & 0.78 & nephrosclerosis & - \\
\hline
\end{tabular}

FSGS: focal segmental glomerulosclerosis.

with a moderate prevalence of global sclerotic glomeruli (9.8\%), but were observed in only a few glomeruli (9.7\%). Two patients showed typical changes of hyaline sclerosis in small arteries, mild mesangial matrix proliferation with little evidence of mesangial cell proliferation, and a higher prevalence of global sclerosis (35\%) than the other cases. In the biopsy specimens, several small foci of tubular atrophy and interstitial fibrosis were present. In one case, IgM and C3 deposition was seen in sclerosed areas of glomeruli. The findings in these two patients suggested benign nephrosclerosis.

Ultrastructual examination by electron microscopy was performed in 5 ( 2 with FSGS and 3 with minimal change) of 10 cases with FSGS and minimal change. In the other cases, 
Insulin Resistance and Proteinuria in Obesity

Table 4. The Changes of Each Parameter during off-on-off Troglitazone

\begin{tabular}{|c|c|c|c|c|c|}
\hline & $\begin{array}{l}\text { Administration of } \\
\text { troglitazone }\end{array}$ & Baseline & $\begin{array}{c}8 \text { weeks after starting } \\
\text { troglitazone }\end{array}$ & $\begin{array}{c}8 \text { weeks after withdrawing } \\
\text { troglitazone }\end{array}$ & Repeated-ANOVA \\
\hline \multirow[t]{2}{*}{ Body weight, $\mathrm{kg}$} & + & $81.5 \pm 12.8$ & $81.4 \pm 14.3$ & $81.5 \pm 14.7$ & \multirow{2}{*}{ NS } \\
\hline & - & $80.9 \pm 6.4$ & $80.5 \pm 7.7$ & $80.9 \pm 9.2$ & \\
\hline \multirow{2}{*}{ Mean arterial pressure, $\mathrm{mmHg}$} & + & $105 \pm 13$ & $104 \pm 10$ & $104 \pm 13$ & \multirow[b]{2}{*}{ NS } \\
\hline & - & $101 \pm 6$ & $104 \pm 12$ & $104 \pm 8$ & \\
\hline \multirow[t]{2}{*}{ Creatinine clearance, $\mathrm{ml} / \mathrm{min}$} & + & $135 \pm 16$ & $130 \pm 8$ & $129 \pm 12$ & \multirow{2}{*}{ NS } \\
\hline & - & $130 \pm 20$ & $128 \pm 22$ & $127 \pm 21$ & \\
\hline \multirow[t]{2}{*}{ Urinary protein, $\mathrm{mg} / \mathrm{day}$} & + & $1.17 \pm 0.59$ & $0.65 \pm 0.37 *$ & $0.94 \pm 0.49^{\dagger}$ & \multirow{2}{*}{$<0.05$} \\
\hline & - & $0.82 \pm 0.42$ & $0.78 \pm 0.45$ & $0.82 \pm 0.42$ & \\
\hline \multirow[t]{2}{*}{ Fasting glucose, $\mathrm{mg} / \mathrm{dl}$} & + & $111 \pm 18$ & $103 \pm 19$ & $109 \pm 12$ & \multirow[b]{2}{*}{ NS } \\
\hline & - & $107 \pm 11$ & $117 \pm 12$ & $110 \pm 12$ & \\
\hline \multirow[t]{2}{*}{ Fasting insulin, $\mathrm{mU} / \mathrm{l}$} & + & $12.9 \pm 3.5$ & $6.0 \pm 2.9 *$ & $12.5 \pm 4.4^{\dagger}$ & \multirow[b]{2}{*}{$<0.05$} \\
\hline & - & $12.3 \pm 2.1$ & $11.9 \pm 1.5$ & $12.2 \pm 2.5$ & \\
\hline \multirow[t]{2}{*}{ HOMA-IR } & + & $3.5 \pm 0.9$ & $1.5 \pm 0.7 *$ & $3.3 \pm 1.0^{\dagger}$ & \multirow{2}{*}{$<0.05$} \\
\hline & - & $3.3 \pm 0.6$ & $3.1 \pm 0.9$ & $3.4 \pm 1.0$ & \\
\hline \multirow[t]{2}{*}{ Urinary sodium excretion, $\mathrm{mEq} / l$} & + & $242 \pm 121$ & $240 \pm 82$ & $240 \pm 82$ & \multirow{2}{*}{ NS } \\
\hline & - & $289 \pm 81$ & $211 \pm 94$ & $255 \pm 58$ & \\
\hline
\end{tabular}

${ }^{*} \mathrm{p}<0.05$, versus baseline (Wilcoxon single-rank test), ${ }^{\dagger} \mathrm{p}<0.05$, versus 8 weeks after starting therapy (Wilcoxon single-rank test). ${ }^{*}$ The change of parameters between both groups were analyzed by repeated-mesurement analysis of variance.
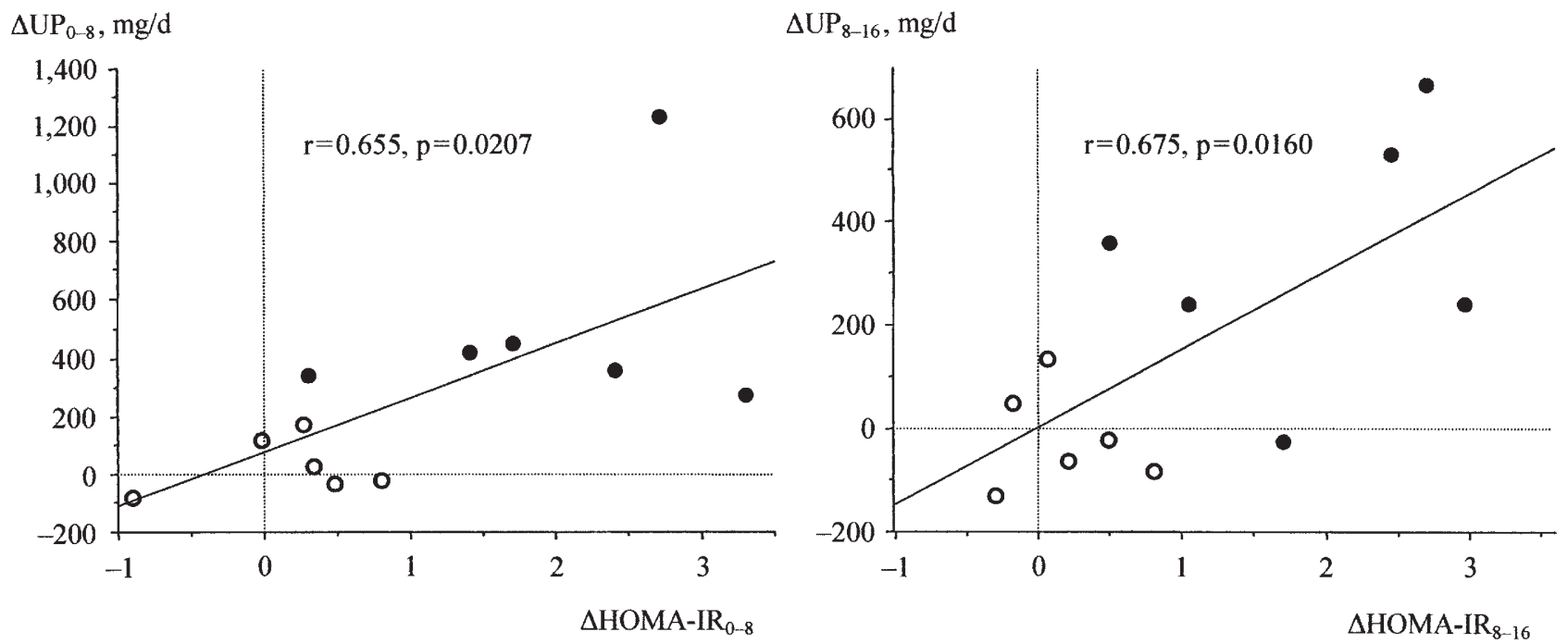

Figure 1. Correlation between change in urinary protein and change in HOMA-IR. Abbreviations are: $\triangle \mathrm{UP}_{0-8}$ and $\Delta \mathrm{HOMA}$ $I_{0-8}$ are the mean changes of urinary protein and HOMA-IR from baseline to after 8 weeks, respectively. $\Delta U P_{8-16}$ and $\triangle H O M A-I_{0-16}$ are the mean changes of urinary protein and HOMA-IR from after 8 weeks to after 16 weeks, respectively. Symbols are: circles are mean patients with troglitazone; solid dots are mean patients without troglitazone.

tissue or blocks of renal tissue were not available. In FSGS, the only abnormality was minimal foot process fusion. Foot process fusion was not observed in minimal change.

Troglitazone was given to 3 patients with minimal change (patients 1,3,5), 2 patients with FSGS (patients 8, 10), and 1 patient with nephrosclerosis (patient 11) (Table 3). There were no differences in baseline parameters between the two groups. After 8 weeks of troglitazone, urinary protein excretion decreased with near normalization of HOMA-IR and serum insulin (Table 4). Eight weeks of cessation of troglita- zone, urinary protein excretion increased with HOMA-IR and fasting serum insulin returned to the baseline value (Table 4). There were no significant changes in body weight, mean arterial pressure, creatinine clearance, fasting glucose, or urinary sodium excretion (Table 4). No variables of patients not treated with troglitazone were affected during the study period (Table 4). In all 12 patients, the changes in urinary protein from baseline to that after 8 weeks correlated with that of HOMA-IR $(r=0.655, \mathrm{p}<0.05)$ (Fig. 1). Also, the changes in urinary protein from after 8 weeks to after 16 
weeks correlated with that of HOMA-IR $(r=0.675, p<0.05)$ (Fig. 1). Neither liver damage nor edema formation was caused by the use of troglitazone for 8 weeks.

\section{Discussion}

Obese individuals commonly develop insulin resistance and resultant hyperinsulinemia. Recent epidemiologic and metabolic evidence has revealed a new concept, regarding obesity or insulin resistance as a common component of the metabolic syndrome. In this study, the obese patients with proteinuria had a higher insulin resistance than the obese controls. An experimental study with obese animals has shown increased renal blood flow and glomerular filtration rate mediated by dilated afferent arterioles (11). A human study with non-diabetic obese subjects documented similar results (5). Hypertension commonly occurred in obese patients (12), therefore, we wonder if the effect of augmented blood pressure is transmitted to the glomerular capillaries through preferential dilated afferent arterioles, resulting in an enhancement of proteinuria via an increased intra-glomerular pressure. Furthermore, most obese patients have difficulty adhering to strict hypocaloric diets (13). Consequently, the overweight state in many will remain, likely resulting in continuous renal hemodynamic abnormalities. Eventually, longstanding alteration of renal hemodynamics might cause glomerulosclerosis.

The common glomerular morphologic finding in obese patients is FSGS $(3,4)$. In the present study, only 3 of the 12 proteinuric patients had FSGS. There may be several reasons. First, routine histologic sections may underestimate the total number of glomeruli affected by focal segmental sclerosis. Second, the lower prevalence of morbid obesity compared with that of previous studies (body mass index over 40 $\mathrm{kg} / \mathrm{m}^{2}$ ) may be responsible for the lower incidence of FSGS. Ultrastructurally, the degree of foot process fusion was minimal, suggesting a different pathomechanism of podocyte injury compared with primary FSGS. Minor glomerular abnormalities are a rare histological finding in obesity in previous reports $(4,14)$. Of interest, 7 of the 12 proteinuric patients had minor glomerular abnormalities. Ultrastructurally, the degree of foot process fusion was not observed. The findings may imply an initial and reversible condition preceding the appearance of focal segmental glomerulosclerosis. The average prevalence of global sclerosis was less prevalent in minimal change lesions, moderately prevalent in FSGS, and highly prevalent in nephrosclerotic glomeruli. It is important for the interpretation of obesity-related nephropathy to understand whether the 3 different renal histologic findings constitute a continuum.

There are strong links between insulin resistance and body mass index, between insulin resistance and blood pressure, and between body mass index and blood pressure $(6,15,16)$. To focus on the role of insulin resistance in relation to obesity-related proteinuria and to clarify the effect of insulin resistance, troglitazone that acts as an insulin sensitizer was administered to 6 patients with proteinuria. Attenuation of insulin resistance after troglitazone was associated with a reduction of proteinuria, but not with a decrease of blood pressure or body mass index. Ogihara et al reported a decrease in serum insulin and improvement of blood pressure by administration of troglitazone in patients with mild essential hypertension complicated by NIDDM (17). In this respect, a condition of habitual salt intake in the present study may be responsible for different results against conditions of salt restriction for Ogihara's study. The reducing effect of troglitazone on proteinuria without any change in blood pressure is a valuable finding because previous studies could not exclude the effect of concomitant hypertension on proteinuria in obesity. The determinants of obesity-related proteinuria still remain unknown, but insulin may be involved. Increased sympathetic output are characteristics of obesity (18). Juncos and Ito documented that insulin reduces norepinephrineinduced efferent arteriolar constriction in a study of isolated rabbit glomerular vessels (7), suggesting that insulin resistance on glomerular vessels results in glomerular hypertension through efferent arteriolar vasoconstriction. As another candidate, leptin may play an important role in the microcirculation of obesity because one study suggested that thiazolidinediones inhibit leptin production and ameliorate albuminuria in the streptozotocin diabetic rat and in type 2 diabetic patients (19).

Potential limitations of the present study should be noted. First, clinical parameters run short of assessing renal filtration dynamics. Therefore, we cannot determine whether the beneficial effect of troglitazone is a consequence of improved renal hemodynamics abnormalities based on the amelioration of insulin resistance. We consider that the constant value of creatinine clearance alone, seen during the present study, cannot explain the lack of hemodynamic effect caused by reducing proteinuria. Second, obese patients with proteinuria had a higher body mass index than controls. To intensify the relationship between insulin resistance and obesityrelated proteinuria, we should select obese controls with a similar body mass index as obese patients with proteinuria.

In conclusion, the amelioration of insulin resistance in obesity is associated with a reduction of proteinuria. The role of insulin resistance as a factor contributing to the glomerular hemodynamics changes remains to be clarified.

Acknowledgements: The authors are indebted to Professor J. Patrick Barron of the International Medical Communications Center of Tokyo Medical University for his review of the manuscript.

\section{References}

1) Weisinger JR, Kempson RL, Eldridge FL, Swenson RS. The nephrotic syndrome: A complication of massive obesity. Ann Intern Med 81: 440-447, 1974.

2) Kasiske BL, Napier J. Glomerular sclerosis in patients with massive obesity. Am J Nephrol 5: 45-50, 1985.

3) Praga M, Hernandez E, Morales E, et al. Clinical features and longterm outcome of obesity-associated focal segmental glomerulo- 


\section{Insulin Resistance and Proteinuria in Obesity}

sclerosis. Nephrol Dial Transplant 16: 1790-1798, 2001.

4) Kambham N, Markowitz GS, Valeri AM, Lin J, D'Agati VD. Obesityrelated glomerulopathy: An emerging epidemic. Kidney Int 59: 14981509, 2001.

5) Chagnac A, Weinstein T, Korzets A, Ramadan E, Hirsch J, Gafter U. Glomerular hemodinamics in severe obesity. Am J Physiol Renal Physiol 278: F817-F822, 2000.

6) DeFronzo RA, Ferrannini E. Insulin resistance: a multifaceted syndrome responsible for NIDDM, obesity, hypertension, dyslipidemia, and atherosclerotic cardiovascular disease. Diabetes Care 14: 173-194, 1991.

7) Juncos LA, Ito S. Disparate effects of insulin on isolated rabbit afferent and efferent arterioles. J Clin Invest 92: 1981-1985, 1993.

8) Kuzuya T, Nakagawa S, Satoh J, et al. Reports of the Committee on the Classification and Diagnostic Criteria of Diabetes Mellitus. Diabetes Res Clin Pract 55: 65-85, 2002.

9) Matthews DR, Hosker JP, Rudenski AS, Naylor BA, Treacher DF, Turner RC. Homeostasis model assessment: Insulin resistance and beta-cell function from fasting plasma glucose and insulin concentrations in man. Diabetologia 28: 412-419, 1985.

10) Laakso M. How good a marker is insulin level for insulin resistance? Am J Epidemiol 137: 959-965, 1993.

11) Hall JE, Brandsy MW, Henegar JR, Shek EW. Abdominal kidney function as a cause and consequence of obesity hypertension. Clin Exp
Pharmacol Physiol 25: 58-64, 1998.

12) Ribstein J, du Cailar G, Mimran A. Combined renal effects of overweight and hypertension 28: 610-615, 1995.

13) Foster GD, Wadden TA, Makris AP, et al. Primary care physicians' attitudes about obesity and treatment. Obes Res 11: 1168-1177, 2003.

14) Wesson DE, Kurtzman NA, Frommer JP. Massive obesity and nephrotic proteinuria with a normal renal biopsy. Nephron 40: 235 237, 1985.

15) McLaughlin T, Allison G, Abbasi F, Lamendola C, Reaven G. Prevalence of insulin resistance and associated cardiovascular disease risk factors among normal weight, overweight, and obese individuals. Metabolism 53: 495-499, 2004.

16) Bianchi S, Bigazzi R, Valtriani $C$, et al. Elevated serum insulin levels in patients with essential hypertension and microalbuminuria. Hypertension 23: 681-687, 1994.

17) Ogihara T, Rakugi H, Ikegami H, Mikami H, Masuo K. Enhancement of insulin sensitivity by troglitazone lowers blood pressure in diabetic hypertensives. Am J Hypertens 8: 316-320, 1995.

18) Rocchini AP, Key J, Bondie D, et al. The effect of weight loss on the sensitivity of blood pressure to sodium in obese adolescents. N Engl $\mathrm{J}$ Med 31: 580-585, 1989.

19) Guan Y, Breyer MD. Peroxisome proliferator-activated receptor (PPARs): novel therapeutic targets in renal disease. Kidney Int 60: 14 $30,2001$. 